\title{
THE INTRACAROTID AMOBARBITAL PROCEDURE (WADA TEST) WITH TWO PROTOCOLS COMBINED, MONTREAL AND SEATTLE
}

\author{
PAULO J.M. LEITE , ROSANA PEREIRA***, DIOGO F. ALMEIDA***, MARCOS C. SANDMANN",

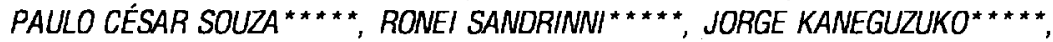 \\ PAULO ROBERTO M. DE BITTENCOURT**
}

\begin{abstract}
The intracarotid amobarbital procedure was carried out in 8 male and 7 female candidates to temporal lobectomy, and a female candidate to frontal lesionectomy, aged 18-50 (mean 32.5) years. Language and memory were tested after injection in each hemisphere. Both were measured by the Montreal procedure. In 9 patients language and memory were evaluated with the Seattle procedure too. In 12 patients the left hemisphere was dominant for language; three had bilateral dominance. In I patient the Seattle procedure demonstrated the dominant hemisphere by relatively slowness of speech during the drug effect in the left hemisphere. Memory was defined to be in the left hemisphere in 12 paticnts, in the right in 2, bilateral in 1 and in another lateralization was not possible. In 1 patient memory dominance was determined by the Montreal protocol alone because of lack of cooperation. These early results indicate that the methods may be complementary for determination of language and memory dominance in epilepsy surgery candidates.
\end{abstract}

KEY WORDS : annobarbital (Wada) test, epilepsy surgery, language, memory.

Procedimentos do amobarbital intracarotídeo (teste de Wada) com dois protocolos combinados, Montreal e Seattle

RESUMO - O testo do amobarbital intracarotídeo foi realizado em 8 homens e 7 mulheres candidatos a lobectomia temporal e em una mulher candidata a lesionectomia frontal, com idades de 18-50 (média 32,5) anos. Linguagem c memória foram testadas após a injeção do amobarbial em cada hemisfério cerebral. Todos os pacientes foram avaliados pelo método de Montreal e 9 também pelo método de Seattle. Em 12 pacientes o hemisfério cerebral esquerdo foi dominantc para linguagem e em 3 pacientes houve dominância bilaternl. Em uma paciente a linguagem foi determinada apenas através do método de Seattle, com lentificação rclativa da fala, sob ação da droga no hemisfério cerebral esquerdo. Dominância da memória à esquerda foi observada em 12 pacientes, ì direita em 2, bilateral $\mathrm{cm}$ I e em outro não foi lateralizada. Dominância da memória foi definida apenas através do método de Montreal em um paciente, devido à pouca cooperação. Estes resultados preliminares indicam que os métodos podem ser complementares para a determinação da dominância da linguagem e memória em especial nos candidatos à lobectomia temporal.

PALAVRAS-CHAVE: teste do amobarbital (Wada), cirurgia de epilepsia. linguagem, memória,

The majority of patients with temporal lobe epilepsy who are refractory to medical treatment and who are submitted to temporal resection have substantial improvement of scizure control ${ }^{\prime \prime}$. The possibility that complications related to memory and language may arise due to the surgical procedurc must be evaluated before surgery ${ }^{4,6,12,13,17}$. The intracarotid amobarbital procedure (Wada test) was introduced by Dr. Juhn Wada to determine the side of hemispheric dominance for language ${ }^{26.27}$. In

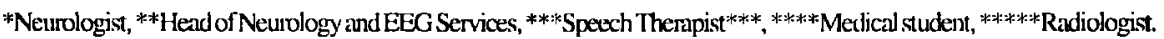
Program of Epilepsy Surgery, Hospital Nossa Senhora das Graças, Curritiba: Aceite: 4-fevereiro- 1997.

Dr. Paulo R. M. de Bittencourt - Unidade de Neurologia Clínica - Rua Padec Anchieta 155 - 80410-030 Curitiba PR - Brasil. 
1960 Milner and colleagues attached to the method the evaluation of memory ${ }^{\prime \prime}$. The procedure of the amobarbital test is done in different ways in various epilepsy centers around the world 1.4 .4 .1 . 12.15.10.211. Recently the amobarbital procedure has been proposed as an additional method for the lateralization of the epileptogenic area in paticnts with temporal lobe epilepsy ${ }^{8.13 .21}$.

Language deficits have been described after temporal ressection ${ }^{5.25}$, but memory is the critical issue, to which more attention has been given ${ }^{4.3 .14 .19 .20 .23 .2 \mathrm{~K}}$. Global amnesia has been reported after temporal lobectomics in only a few cases in the history of epilepsy surgery ${ }^{4,10}$. But selective deficits of certain aspects of memory arc known to take place more commonly and they have been extensively discussed in the literature $e^{4.12 .17 .19 .23 .25}$. When surgery in the dominant hemisphere involves the posterior part of the temporal lobe, certain frontal or parietal regions, cortical language mapping techniques may indicated ${ }^{3.5 .1 \%}$.

The objective of this study was to compare the clinical use of two routincs of the amobarbital (Wada) test. We used the protocols used in Montreal ${ }^{7}$ and in Seattle ${ }^{4}$. These protocols were designed to lateralize memory, language and epileptogenic area in patients with temporal lobe epilepsy who are candidates to temporal ressection. This study was designed to analise the value of the combination of Montreal and Seattle IAP protocols for the lateralization of memory and language dominance, and has been published as an abstract ${ }^{10}$.

\section{METHODS}

This study was carried out in patients evaluated by Hospital Nossa Senhora clas Graças Epilepsy Surgery Program²1. Patients were asked to undergo the amobarbital (Wada) test when a presurgical investigation indicated that they were good candidates for surgery involving eloquent cerebral regions. All patients underwent a structured investigation including medical, neurological, psychiatric and neuropsychological evaluation. Prolonged monitoring with digital videoclectroencephalography was carried out with the objective of recording enough ictal and interictal material to locate the epileptogenic area. Sphenoidal electrodes were used in all patients with suspected temporal lobe epilepsy22. Patients who at the end of this investigation still needed additional invasive investigation, including subdural plates and electrocorticography, were placed on a waiting list for the time when these procedures are fully established in our center.

Specialised imaging procedures including CT and MR were used in all cases. Hippocampal volumes were determined in all cases of possible temporal lobe epilepsy and in many others too, as part of a control group in a separate research project ${ }^{1.11}$. Ictal and interictal SPECT wee carried out in selected cases.

\section{The Curitiba amobarbital procedure}

A brief evluation was carried out before the test, to establish the patient's normal pattern of memory and language. The opportunity was used to familiarize patients with the technique, and to find out how the patients dealt with the less demanding test situation at his hospital room. Any parts of the test, including objetcs or cards, were excluded from the actual test situation if the patient had difficulties with it. The test procedure was carried out in a digital angiography room, by a team used to complex vascular procedures including cmbolization of cerebral vascular or tumotal lesions and intracercbral navigation techniques. The patient was fitted with silver/silver chlorided electrodes for continuous monitoring of the EEG, carried out in a pottable 8-channel analog machine. Patterns of slowing of the EEG activity jpsilateral to the injection were used to define 1!e timing of the tests. A 4-vessel angiogram was carried out to assess the intracranial vasculature. The transfemoral Seldinger technique was used, and specific attention was given to possible side-to-side shunting of the cerebral circulation. Material and equipment were at hand in case selective catheterization of cerebral vesscls was warranted during the test situation.

Each patient underwent catheterization of the internal carotid artery. The amount of amobarbital to be injected was $112 \mathrm{mg}$ for males and $100 \mathrm{mg}$ for females. The solution was prepared by diluting amobarbital $\mathbf{2 5 0}$ $\mathrm{mg}$ ) in $5 \mathrm{ml}$ of saline. The side of surgical interest was injected first, anf after at least 30 ininutes, the other side underwent the same procedure. The Montreal ${ }^{17}$ and the Seattle ${ }^{4}$ procedures were done simultaneously. The Montreal iterns were shown during the Seattle procedure

The Montreal procedure consists of the presentation of 5 visual items during the effect of amobarbital, as defined by the lateralization of the slowing observed in the EEG and by the clinical situation of the patient. After the effect of the drug has disappeared the patient is asked to recognize those items which were presented during the effect of the drug. We considered 4 or more items correct "passing" and fewer than 4 as "failing". The 
hemisphere dominance for memory is defined as the side in which injection induces the patients to make 2 or more errors in the post injection recognition of the 5 items?

The Seattle procedure involves 3 steps: naming of objects, reading phrases and testings of immediate memory. There are 20 different items which are shown continuously over a period of time. Basically the test is carried out continuously during the effect of amobarbital. The result is quantitative, the patient receiving a mak of $0-100 \%$. Error rates of 0 to $49 \%$ are considered "passing" and those "failing" are $50 \%$ or more. The clinical effect of the amobarbital is contralateral hemiplegia and speech dysfunction if this is the speech clominant lemisphere, occurring immediately upon right injection of the drug. The EEG shows a diffuse slowing followed by a lateralization of delta waves in the ipsilateral hemisphere. When the effect of amobarbital has waned, usually some 1.5 minttes after the injection, the visual items are presentend to the patient together with other items. The patient is then asked to chose the items that had been shown during the effect of amobaibital ${ }^{4}$. In both procedures language dominance is evaluated during the test of memory, by the observation of errors in naming, speech blockarle and receptive and expressive dysphasia.

\section{RESULTS}

We cvaluated 16 patients in the period between February 1994 and February 1996. There were 8 males and 7 females with refractory temporal lobe epilepsy and 1 female with refractory frontal lobe epilepsy secondary to trauma. They were aged 18-50 years (Table 1). Seven of those patients were submitted only to the Montreal procedure, and nine to both protocols. Twelve of the patients were shown to be left hemisphere dominant for language and three had bilateral language dominance. In one patient language dominance could be determined in a definitive manner by the Seattle procedure only. The patient did not have a dysphasia or speech blockage, only slowness of speech during testing when was compared to the non-dominant hemisphere.

Table I. Results of the intracarorid anobarbital (Wada) procedure.

\begin{tabular}{|c|c|c|c|c|c|}
\hline Patient & Age & Sex & IQ & Speech domiance (M/S) & Memory dominance (M/S) \\
\hline RMK & 43 & f & 95 & left/- & left/- \\
\hline RTM & 33 & i & 97 & none/left & left/left \\
\hline AA & 30 & f & 89 & left/- & left/- \\
\hline LCS & 32 & m & 117 & left/- & tight/- \\
\hline VH & 18 & $\mathrm{~m}$ & 104 & bilateral/- & right/- \\
\hline RAP & 32 & $\mathrm{f}$ & 82 & left/left & left/left \\
\hline ОВD & 30 & $\mathrm{~m}$ & 67 & bilateral/bilateral & left/none \\
\hline $\mathrm{CGF}$ & 37 & $\mathrm{f}$ & 102 & left/left & left/none \\
\hline MAB & 38 & $f$ & 95 & left/- & left/- \\
\hline ES & 23 & $f$ & 94 & bilateral/bilateral & bilateral/bilateral \\
\hline $\mathrm{OB}$ & 50 & m & 93 & left'- & left/- \\
\hline $\mathrm{HCC}$ & 32 & $\Gamma$ & 88 & leftleft & leftleft \\
\hline JDF & 21 & $\mathrm{~m}$ & 75 & left/left & none/none \\
\hline AR & 34 & 111 & 94 & left/- & left- \\
\hline VHM & 29 & $\mathrm{~m}$ & 106 & left/left & left/left \\
\hline NM & 38 & $\mathrm{~m}$ & 105 & left/left & left/left \\
\hline
\end{tabular}


Mcmory dominance was determined to be in the left hemisphere in 12 patients, in the right hemisphere in two and bilateral in one patient. In one patient (n.1, Table 1) memory dominance was determined by the Montreal procedure alonc. In another patient memory lateralization was not possible with either method. This particular patient was submitted to a left temporal lobectomy without any relevant changes in memory after surgery. One of the bilateral dominant patients had suffered trauma eraly in life. In one patient with boderline IQ, memory dominance was determined by the Montreal procedire alone, because cooperation was not compatible with the performance needed for the Seattle procedure.

Lateralization of the epilcptogenic area by the amobarbital procedure was correlated with EEG and MRI in 11 of 15 patients. Four patients were submitted to temporal lobectomy on the dominant hemisphere. In one surgery did not improve seizure control. Two have had greater than $80 \%$ improvement in seizure frequency; 6 patients are seizure free. Two are scheduled to have invasive monitoring before their epileptogenic area can be resected.

Follow-up of the patients submitted to surgery is $2-24$ (mean 12.7) months. Two of the patients have complained of neurological or psychiatric deficits after the temporal lobectomy. In one case the patient had a major depressive episode after surgery; the other patient developed a resersible hemiparesis contralateral to a right temporal lobectomy. In another case the patient reported a worsening of her preoperative memory deficit. She, as well as the others, have not had deficits demonstrated on clinical or specific testing, when pre and post-operative testing with the WAIS and Weschler memory scales was compared. In one case memory and speech were determined to be on the same side of the epileptogenic region, the left temporal lobe. The patient underwent a resection of the more medial aspects of the left temporal lobe, rather than en-bloc resection. The paticnt has been seizure free for 12 months. In another case of left temporal lobectomy with bilateral dominance for memory (patient n. 13, Table 1) no significant deficit was documented after surgery.

\section{DISCUSSION}

The objective of this paper was to evaluate the efficacy of two different protocols of the Wada (amobarbital) test in the determinantion of language and memory dominance in candidates to temporal lobectomy. Our experience suggest that there may be critical differences between the two methods. In the Seattle ${ }^{4}$ procedure memory performance is evaluated during the effect of the drug. Consequently it gives a more comprehensive report of the state of memory and language during the test session. The Seattle procedure is complex for patients and for those carrying out the tests, and some patients are not able to perform well enough in the test environment and cannot complete the procedure. The Montreal ${ }^{7}$ procedure is simple, fast, and relatively casy for patients and for those carrying out the test.

Languagc function is assessed more comprehensively by the Seattle procedure ${ }^{4}$. In one of our cases a rare situation occurred: we could only lateralize language because of a relative slowing of speech during the effect of the amobarbital in the left hemisphere. In this particular case the patient had no dysphasia or naming error during the drug effect in the left hemisphere. In two patients lateralization of memory was only possible with the Montreal ${ }^{7}$ procedure. The patient with boderline IQ did not collaborate enough for the Seattle procedure; another patient had no demonstrable mcmory deficit with the Seattle procedure with injection in either hemisphere.

The amobarbital (Wada) test ${ }^{16.26 .27}$ has been incorporated in our surgical program as one of its

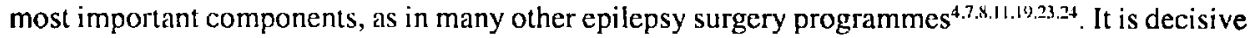
for assuring patients and physicians that resection of the epileptogenic region will not lead to significant memory or language deficits. Our data may support the concept that the Wada test may be one more factor to indicate the laterality of the epileptogenic region, once it has been shown to be in one of the temporal lobes. Our results may indicate that the methods are complementary for determination of 
language and memory dominance in candidates to temporal lobectomies. We intend to continue using the procedurc as specified here, with the following specifications: routine bilateral injections into the internal carotids; assessment of effect of amobarbital by EEG and clinical evaluation of hemiplegia and alertness; use of the Montreal and Seattle procedures concomitantly.

Acknowledgment - The authors wish to thank Dr Carl B Dodrill (Seattle, USA) for the advice he has continuously given to the team of the Program for Epilcpsy Surgery of Hospital Nossa Senhora das Graçs.

\section{REFERENCIAS}

1. Bittencourt PRM. Epileptogênese, estrutura e funçūo cerebral na epilepsia do lobo temporal: um estudo prospectivo controlado. Thesis for the degree of Professor of Medicine (Neurology), Universidade Federal do Puraná. Curitiba, 1991.

2. Blıme WT. Grabow ID, Darley FL, Aronson AE. Intracarotid amobarbital test of language and memory before temporal lobectomy for seizure control. Neurology 1973;23:812-819.

3. Davis AE, Wilda JA. Speech dominance and handedness in the normal human. Brain \& Language 1978;5:42-45.

4. Dodrill CB. Propxrative criteria for identifying eloquent brain: intracarotid amytal for languige and memory testing. Neurosurg Clin North Am 1993:4:2 II-2! 5.

5. Hernimn BP, Wyler AR. Sonws G. Language function fol lowing anterior temporal lobectomy. J Neurosurg 1991;74:560-566

6. Ivnic RJ, Sharbrough FW. Laws ER. Auterior temporal lobectomy for the control of pintial complex seizures: informition for counseling palients. Mayo Clin Proc 1988;63:783-793.

7. Jones-Gotman M. Commentary: psyclsological evaluation-testing hippocinpal function. In J Engel (ed). Surgical treatment of line epilepsies. New York: Raven Press, 1987:203-211.

8. Knebbone AC. Chelune GJ. Dinner DS, Naugle RI. Awad IA. Intracirotid amobarbital procedure as predictor of malerialspecific memory change after allerior temporal lobectony. Epilepsia 1995;36:857-865.

9. Lee GP, Loring DW, Snith JR, Flanigin HF. Intraoperative hippocampal cooling and Wada memory in the evaluation of amnesia risk following anterior temporal lobectomy. Arch Neurol 1995;52:857-861.

10. Leite PJM, Percira R. Sindmann MC, Souza PC, Sandrinni RA, Kaneguzuko J. Bittencourt PRM. Intracarotid amobarbital procedure with the Montreal and Seattle protocols combined. (Abst). 2 lst Internitional Epilepsy Congress. Sydney, Australial, 1995, Vol 36 (Suppl 3): 123.

11. Lesser RP, Dimner DS, Luders H. Morris HH. Memory for objects presented soon after intracarotid almobalbital sodium injections in patients with nedically intractuble complex partial seizures. Neurology 1986;36:895-899.

12. Loring DW, Lee GP. Meidor KJ. Flanigin HF, Smith JR, Figueroa RE, Martin RC. The intricitotid amobarbital procedure as a predictor of memory tailute following uniliteral temporal lobectomty. Neurology 1960;40:605-610.

13. Loring DW, Meador KJ, Lee GP. Nichols ME, King DW, Gallgher BB, Murro AM, Snith JR. Wada memory perfornance predicts scizure outcome following anterior temporal lobectomy. Neurology 1994;44:2322-2324.

14. Loring DW, Meidor KJ, Lee GP, King DW, Gallagher BB, Murro AM. Snith JR. Stimulus timing effects on Wiuda memory lesting. Arch Neurol 1994:51:806-8!0.

15. Loring DW, Murro AM, Meider KI, Lee GP, Gratton CA, Nichols ME. Gallagher BB. King DW, Snith JR. Wada memory testing and hippocimpil volume measurements in the evaluation tol temporal lobectomy. Neurology 1993;43:1789-1793.

16. Milner B. Brench C, Resmussen T. Study of short-term memory after intacatotid injection of sodium anmytal. Trans Am Neurol Assoc 1962:87:224-226.

17. Ojeminn GA. Dodrill CB. Verbill memory deficits after left temporal lobectomy for epilepsy. I Neurosurg 1985:62:101-107.

18. Ojemann GA, Ojemann BAJ. Lettich E. Berger M. Cortical language localization in left dominant hemisphere: an electrical stimulation mapping investigation in 117 patients. J Neurosurg 1989;71:316-326.

19. Perrine K. Gershengorn I, Brown ER. Choi IS, Luciano DJ, Devinski O. Matterial-specitic menory in the intricarotid amobarbital procedure. Neurology 1993;43:706-711.

20. Rallisch R. Babb TL, Engel J JR. Criandall PH. Memory following intraci[rotid amobarbital injection contralateral to hippocimpal damage. Arch Neurol 1989;39:783-788.

21. Silndmann MC. Leite PJM, Pontex L, Bittencourt PRM. Early results of a new epilepsy surgery program. (Abst). 21st International Epilepsy Congress. Sydney, Australia. 1995. Vol 36 (Suppl 3):259.

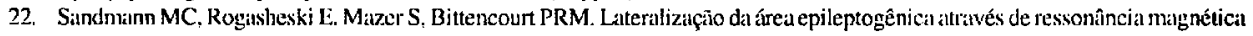
na cpilepsia do lobo itmponal. Arq Neuropsiquiatr 1994;52:309-313.

23. Siss KI. Lencz T. Westerveld M. Novelly RA. Spencer DD, Kim JH. The neurul substrate of nemory impairment demonstruted by the intracirotid imobirbitil procedure. Arch Neurol $1991 ; 48: 48-52$.

24. Sperling MR, Siykin AJ, Glosser G. Morin M, French JA, Brooks M, O'Connor MJ. Predictors of outcone after anterior temporal lobectony: the intricitrotid amobubital test. Neurology 1994:44:2325-2330.

25. Statiniak P, Stykin A.I. Sperling MR, Kester DB, Robinson LJ, O'Connor MJ, Gur RC. Acute naming deficits following dominant temporal lobectomy: prediction by age at I st risk for scizures. Neurology 1990;40: 1509-15।2.

26. Wada J. A new method for the determinition of the side of cerebral speech dominance: apreliminary report on the intracarotid injection of sodium anytal in man. Igaku to Seibutsugaki 1945;14:221-222.

27. Wida J, Rasmussen T. Intraciurotid injection of sodjum amyta! for the lateralization of cerebral speech dominance: experimental and clinical observations. J Neurosurg 1960;17:266-282.

28. Wyllic E. Niugle R, Awid I. Chelune G, Luders H, Dinner D, Skibinski C, Ahl J. Intracirotid innobaıbital procedure: prediction of decrcased modality-specific memory scores after tempoial lobectomy. Lilepsia 1991;32:857-864. 